NASA TECHNICAL

MEMORANDUM

NASA TM $X-64595$

DETERMINATION OF STATISTICS FOR ANY

ROTATION OF AXES OF A BIVARIATE

NORMAL ELLIPTICAL DISTRIBUTION

By Lee W. Falls and Harold L. Crutcher

Aero-Astrodynamics Laboratory

May 11, 1971

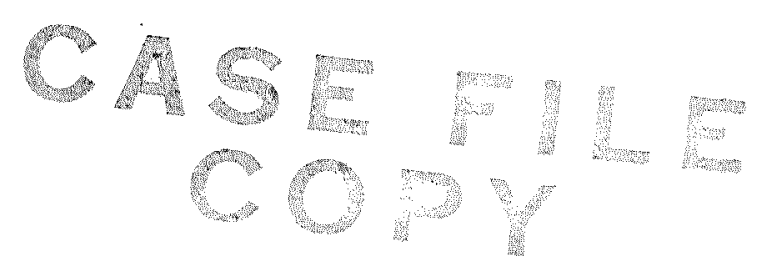

NASA

George C. Marshall Space Flight Center

Marshall Space Flight Center, Alabama 


\begin{tabular}{|c|c|}
\hline $\begin{array}{l}\text { 1. REPORT NO. } \\
\text { NASA TM X-64595 }\end{array}$ & 3. RECIPIENT'S CATALOG NO. \\
\hline \multirow{2}{*}{$\begin{array}{l}\text { 4. TITLE AND SUBTITLE } \\
\text { DETERMINATION OF STATISTICS FOR ANY ROTATION OF AXES OF A } \\
\text { BIVARIATE NORMAL ELLIPTICAL DISTRIBUTION }\end{array}$} & $\begin{array}{l}\text { 5. REPORT DATE } \\
\text { MaY 11, } 1971 \\
\end{array}$ \\
\hline & 6. PERFORMING ORGANIZATION CODE \\
\hline $\begin{array}{l}\text { 7. AUTHOR(S) } \\
\text { Lee W. Falls and Harold L. Crutcher* }\end{array}$ & 8. PERFORMING ORGANIZATION REPORT \\
\hline \multirow{2}{*}{$\begin{array}{l}\text { 9. PERFORMING ORGANIZATION NAME AND ADDRESS } \\
\text { George C. Marshall Space Flight Center } \\
\text { Marshall Space Flight Center, Alabama } 35812\end{array}$} & 10. WORK UNIT NO. \\
\hline & 11. CONTRACT OR GRANT NO. \\
\hline \multirow[t]{2}{*}{$\begin{array}{l}\text { 12. SPONSORING AGENCY NAME AND ADDRESS } \\
\text { NASA } \\
\text { Washington, DC } 20546\end{array}$} & $\begin{array}{l}\text { 13. TYPE OF REPORT \& PERIOD COVERED } \\
\text { TECHNICAL MEMORANDUM }\end{array}$ \\
\hline & 14. SPONSORING AGENCY CODE \\
\hline
\end{tabular}

15. SUPPLEMENTARY NOTES

16. ABSTRACT

A method is presented for the determination of the estimates of means, variances, covariances, and correlations for any rotation of axes of a bivariate normal elliptical distribution. This problem arises in connection with vehicle launches at Cape Kennedy, Florida, when winds normal and parallel to the vehicle flight path are launch constraints. A vector wind data sample is resolved into wind components in a rectangular coordinate system, and the bivariate normal elliptical distribution theory is applied to the data sample of component winds. However, theoretical inferences are required for any arbitrary firing azimuth of the launch vehicle. This requires a rotation of axes of the bivariate normal surface and the computation of new statistics after rotation.

*U. S. Dept. of Commerce, NOAA, Environmental Data Service, National Climatic Center, Asheville, North Carolina.

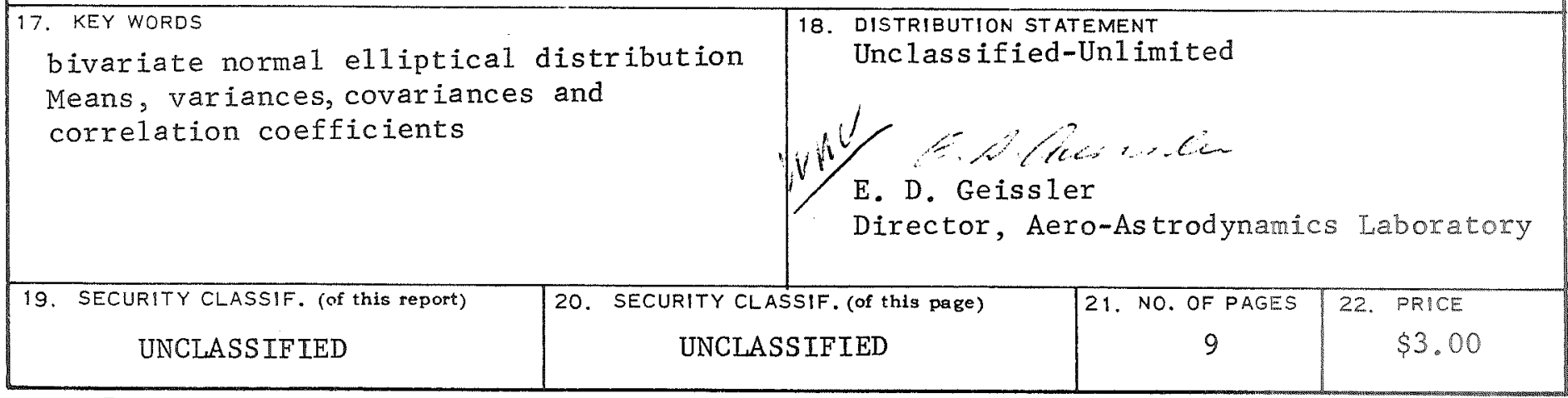




\title{
DETERMINATION OF STATISTICS FOR ANY ROTATION OF AXES \\ OF A BIVARIATE NORMAL ELLIPTICAL DISTRIBUTION
}

\author{
SUMMARY
}

\begin{abstract}
A method is presented for the determination of the estimates of means, variances, covariances, and correlations for any rotation of axes of a bivariate normal elliptical distribution. This problem arises in connection with vehicle launches at Cape Kennedy, Florida, when winds normal and parallel to the vehicle flight path are launch constraints. A vector wind data sample is resolved into wind components in a rectangular coordinate system, and the bivariate normal elliptical distribution theory is applied to the data sample of component winds. However, theoretical inferences are required for any arbitrary firing azimuth of the launch vehicle. This requires a rotation of axes of the bivariate normal surface and the computation of new statistics after rotation.
\end{abstract}

\section{INTRODUCTION}

In 1846, Bravais [1] presented the theory of normal frequency distributions in two and more variables. Most modern statistical textbooks include some discussion of such distributions. Outstanding contributions are notable in the works of Bertrand [2], Czuber [3], Pearson [4], Kluyver [5], and Student [6].

Further developments and some practical applications of these distributions with particular regard to geophysical problems are presented by Crutcher and Baer [7], Crutcher and Moses [8], and Groenewoud, Hoaglin, Vitalis, and Crutcher [9]. Anderson [10] and Hald [11] treat the subject in general form. This report presents a method for the determination of the estimates of means, variances, covariances, and correlations for any rotation of axes of a bivariate normal elliptical distribution. Although the procedure can be extended to the case for more than two variables, this case is not discussed here.

This problem arises in the determination of probabilities of successful launches at Cape Kennedy, Florida. For example, winds exceeding some given value normal and parallel to the flight path may be defined as launch constraints. Those winds normal to the flight path are designated as right and left cross winds, while those parallel to the flight path. 
are called head and tail winds. A vector wind data sample is resolved into wind components in a rectangular coordinate system and the bivariate normal elliptical distribution theory is applied to the data sample of component winds. However, theoretical inferences are required for any axbitrary firing azimuth of the launch vehicle. Making such inferences requires a rotation of the axes of the bivariate normal surface and the computation of new statistics after rotation.

\section{THE BIVARIATE NORMAL ELLIPTICAL DISTRIBUTION}

Let $x_{1}$ and $x_{2}$ be normally distributed variables with parameters $\left(\xi_{1}, \sigma_{1}\right)$ and $\left(\xi_{2}, \sigma_{2}\right) . \xi_{1}$ and $\xi_{2}$ are the respective means, while $\sigma_{1}$ and $\sigma_{2}$ are the respective standard deviations. Let $\rho$ be the correlation coefficient, which is a measure of the dependence between $x_{1}$ and $x_{2}$. Now, the equation of the two-dimensional normal density function takes the form

$$
\begin{aligned}
p\left(x_{1}, x_{2}\right) & =\left(2 \pi \sigma_{1} \sigma_{2}\left[1-\rho^{2}\right]^{1 / 2}\right)^{-1} \exp \left\{-\left(2\left[1-\rho^{2}\right]\right)^{-1}\left[\left(\frac{x_{1}-\xi_{1}}{\sigma_{1}}\right)^{2}\right.\right. \\
& \left.\left.-2 p\left(\frac{x_{1}-\xi_{1}}{\sigma_{1}}\right)\left(\frac{x_{2}-\xi_{2}}{\sigma_{2}}\right)+\left(\frac{x_{2}-\xi_{2}}{\sigma_{2}}\right)^{2}\right]\right\} .
\end{aligned}
$$

Given the variables $x_{1}$ and $x_{2}$, we calculate the estimates of the bivariate normal parameters. Denote the estimates as $\overline{\mathrm{X}}_{1}, \overline{\mathrm{X}}_{2}, \mathrm{~S}_{\mathrm{X}_{1}}, \mathrm{~S}_{\mathrm{X}_{2}}$, and $r_{x_{1} x_{2}}$. A special case of the problem described here is to determine the estimates of the parameters where a rotation of the axes through an angle $\alpha$ reduces the correlation of components to zero. This case is discussed in Crutcher and Baer [7], and Groenewoud, Hoaglin, Vitalis, and Crutcher [9]. From the statistics in the $\left(x_{1}, x_{2}\right)$ space, we must determine the statistics for any rotation of the axes through an arbitrary angle $\alpha$ in the following way.

Let $\left(\mathrm{y}_{1}, \mathrm{y}_{2}\right)$ be the new space after rotation with orthogonal axes $y_{1}$ and $y_{2}$.

$$
\begin{aligned}
& \mathrm{Y}_{1}=\mathrm{X}_{1} \cos \alpha+\mathrm{X}_{2} \sin \alpha \\
& \mathrm{Y}_{2}=\mathrm{X}_{2} \cos \alpha-\mathrm{X}_{1} \sin \alpha,
\end{aligned}
$$


where $\alpha$ is the angle of rotation, and $x_{1}$ and $x_{2}$ are the original axes along which the values of $\mathrm{X}_{1}$ and $\dot{\mathrm{X}}_{2}$ are measured. Denote the sample variances of $\left(x_{1}, x_{2}\right)$ as $s_{x_{1}}^{2}$ and $s_{x_{2}}^{2}$, respectively. The covariance of
$\left(x_{1}, x_{2}\right)$ is

$$
S_{x_{1} x_{2}}=r_{x_{1} x_{2}} S_{x_{1}} S_{x_{2}}
$$

For the special case when $\mathrm{S}_{\mathrm{x}_{1} \mathrm{x}_{2}}$ or $\mathrm{r}_{\mathrm{x}_{1} \mathrm{x}_{2}}$ is equal to zero, the variancecovariance matrix is

$$
\left[\begin{array}{ll}
\mathrm{s}_{\mathrm{x}_{1}}^{2} & \mathrm{~s}_{\mathrm{x}_{1} \mathrm{x}_{2}} \\
\mathrm{~S}_{\mathrm{x}_{2} \mathrm{x}_{1}} & \mathrm{~s}_{\mathrm{x}_{2}}^{2}
\end{array}\right]=\lambda\left[\begin{array}{ll}
1 & 0 \\
0 & 1
\end{array}\right]=\lambda I
$$

or

$$
\left[\begin{array}{ll}
s_{\mathrm{x}_{1}}^{2}-\lambda & s_{\mathrm{x}_{1} \mathrm{x}_{2}} \\
\mathrm{~s}_{\mathrm{x}_{2} \mathrm{x}_{1}} & \mathrm{~s}_{\mathrm{x}_{2}}^{2}-\lambda
\end{array}\right]=0
$$

Setting the determinant of this matrix equal to zero and solving for the two roots of the quadratic equation is essentially the rotation of axes through an angle $\alpha$ to where components along the new axes are uncorrelated. Thus, the roots $\lambda_{1}$ and $\lambda_{2}$ are the variances along the major and minor axes, respectively, of the bivariate distribution and the covariances (correlations) are zero. From these data, variances and covariances (correlations) along any set of new axes can be determined by rotating the axes from this basic position. Then the matrix will be 


$$
\left[\begin{array}{ll}
\mathrm{s}_{\mathrm{y}_{1}}^{2} & \mathrm{~s}_{\mathrm{y}_{1} \mathrm{y}_{2}} \\
\mathrm{~s}_{\mathrm{y}^{2} \mathrm{y}_{1}} & \mathrm{~s}_{\mathrm{y}_{2}}^{2}
\end{array}\right]
$$

where the new space is $\left(y_{1}, y_{2}\right)$ and $y_{1}$ and $y_{2}$ are the axes.

The statistics in the $\left(y_{1}, y_{2}\right)$ space may be derived as follows: Let $\vec{Y}_{1}, \vec{Y}_{2}, S_{y_{1}}^{2}, S_{y_{2}}^{2}, S_{y_{1} y_{2}}, r_{y_{1} y_{2}}$ be the means, variances, covariance, and correlation coefficient in the $\left(\mathrm{y}_{1}, \mathrm{y}_{2}\right)$ space. Taking mathematical expectations of equations (1) and (2), we have for the new means

$$
\begin{aligned}
& \overline{\mathrm{Y}}_{I}=\overline{\mathrm{X}}_{1} \cos \alpha+\overline{\mathrm{X}}_{2} \sin \alpha \\
& \overline{\mathrm{Y}}_{2}=\overline{\mathrm{X}}_{2} \cos \alpha-\overline{\mathrm{X}}_{I} \sin \alpha .
\end{aligned}
$$

Subtracting equation (3) from equation (1), we have

$$
\left(\mathrm{X}_{1}-\overline{\mathrm{Y}}_{1}\right)=\left(\mathrm{X}_{1}-\overline{\mathrm{X}}_{1}\right) \cos \alpha+\left(\mathrm{X}_{2}-\overline{\mathrm{X}}_{2}\right) \sin \alpha
$$

and subtracting equation (4) from equation (2), we have

$$
\left(Y_{2}-\bar{Y}_{2}\right)=\left(X_{2}-\bar{X}_{2}\right) \cos \alpha-\left(X_{1}-\bar{X}_{1}\right) \sin \alpha
$$

Let

$$
\begin{aligned}
& x_{1}=\left(X_{1}-\bar{X}_{1}\right) \\
& x_{2}=\left(X_{2}-\bar{X}_{2}\right) \\
& y_{1}=\left(Y_{1}-\bar{Y}_{1}\right) \\
& y_{2}=\left(Y_{2}-\bar{Y}_{2}\right)
\end{aligned}
$$

be the deviations from the respective means. Now, equations (5) and (6) become 


$$
\begin{aligned}
& \mathrm{y}_{1}=\mathrm{x}_{1} \cos \alpha+\mathrm{x}_{2} \sin \alpha \\
& \mathrm{y}_{2}=\mathrm{x}_{2} \cos \alpha-\mathrm{x}_{1} \sin \alpha .
\end{aligned}
$$

Squaring equations (7) and (8) gives

$$
\begin{aligned}
& y_{1}^{2}=x_{1}^{2} \cos ^{2} \alpha+x_{2}^{2} \sin ^{2} \alpha+2 x_{1} x_{2} \cos \alpha \sin \alpha \\
& y_{2}^{2}=x_{2}^{2} \cos ^{2} \alpha+x_{1}^{2} \sin ^{2} \alpha-2 x_{1} x_{2} \cos \alpha \sin \alpha .
\end{aligned}
$$

Now, taking expected values of equations (9) and (10), we have for the new variances in the $\left(y_{1}, y_{2}\right)$ space

$$
\mathrm{s}_{\mathrm{y}_{1}}^{2}=\mathrm{s}_{\mathrm{x}_{1}}^{2} \cos ^{2} \alpha+\mathrm{s}_{\mathrm{x}_{2}}^{2} \sin ^{2} \alpha+2 \mathrm{~s}_{\mathrm{x}_{1} \mathrm{x}_{2}} \cos \alpha \sin \alpha
$$

and

$$
s_{\mathrm{y}_{2}}^{2}=S_{\mathrm{x}_{2}}^{2} \cos ^{2} \alpha+s_{\mathrm{x}_{1}}^{2} \sin ^{2} \alpha-2 \mathrm{~s}_{\mathrm{x}_{1} \mathrm{x}_{2}} \cos \alpha \sin \alpha
$$

To derive the covariance, $\mathrm{S}_{\mathrm{y}_{1}} \mathrm{y}_{2}$, in the $\left(\mathrm{y}_{1}, \mathrm{y}_{2}\right)$ space, we multiply equation (7) by equation (8) and obtain

$$
y_{1} y_{2}=x_{1} x_{2}\left(\cos ^{2} \alpha-\sin ^{2} \alpha\right)+\cos \alpha \sin \alpha\left(x_{2}^{2}-x_{1}^{2}\right)
$$

Taking the mathematical expectation of equation (13) gives the covariance in the $\left(y_{1}, y_{2}\right)$ space

$$
S_{y_{1} y_{2}}=s_{x_{1} x_{2}}\left(\cos ^{2} \alpha-\sin ^{2} \alpha\right)+\cos \alpha \sin \alpha\left(s_{x_{2}}^{2}-s_{x_{1}}^{2}\right) .
$$

Finally, the correlation coefficient in the $\left(y_{1}, y_{2}\right)$ space is defined as

$$
r_{y_{1} y_{2}}=\frac{s_{y_{1} y_{2}}}{s_{y_{1}} s_{y_{2}}} .
$$


Equations (3), (4), (11), (12), (14), and (15) give the required estimates of the statistics in the $\left(y_{1}, y_{2}\right)$ space.

A computer program whose input is the statistics in the $\left(x_{1}, x_{2}\right)$ space and any arbitrary angle of rotation of the bivariate normal surface is available upon request. The output of the program includes the required statistics in the $\left(y_{1}, y_{2}\right)$ space. 


\section{REFERENCES}

1. Bravais, A., 1846: Analyse mathematique sur les probabilities des erreurs de situation d'un point, Mem. presentes par divers savants, Acad. Sci. Paris, Mem. Sav. Etrang. 9, pp. 255-332.

2. Bertrand, J., 1888: Calcul des probabilites: Note sur la probabilite du tir a la cible: Troisieme note sur la probabilite du tir a la cible, Compt. Rend. 106, pp. 387-391; pp. 521-522.

3. Czuber, Emanue1, 1891: Theorie der Beobachtungsfehler, B. G. Teubner, Leipzig, pp. 400-411.

4. Pearson, K., 1900: On the criterion that a given system of deviations from the probable in the case of a correlated system of variables is such that it can reasonably be supposed to have arisen from a random sampling, Phil. Mag. 50, pp. 157-175.

5. Kluyver, J. C., 1906: A local probability problem, Proc. Roy. Acad., Amsterdam, pp. 341-350.

6. Student (W. S. Gosset), 1925: New tables for testing the significance of observations, Metron 5, pp. 105-120.

7. Crutcher, H. L. and L. Baer, Dec. 1962: Computations for elliptical wind distribution statistics, Journal of Applied Meteorology, Vol. 1, No. 4, pp. 522-530.

8. Crutcher, H. L. and H. Moses, July 1962-June 1963: A note on ellipsoidal wind distributions, Argonne National Laboratory Radiological Physics Division Summary Report, ANL-6769, pp. 181-196.

9. Groenewoud, C., D. C. Hoaglin, and J. A. Vitalis, Dec. 1967: Bivariate normal offset circle probability tables with offset ellipse transformations, Cornell Aeronautical Laboratory, Inc., Vol. 1 and 2; pp. 1-1320; and H. L. Crutcher, December 15, 1967, Applications to geophysical data, National Weather Records Center, U. S. Department of Commerce, Vo1. 3, pp. 1-44.

10. Anderson, T. W., 1958: An Introduction to Multivariate Analys is, John Wiley and Sons, Inc., New York, pp. 1-374.

11. Hald, A., 1952: Statistical Theory with Engineering Applications, John Wiley and Sons, Inc., New York, pp. 1-783. 


\section{APPROVAL}

DETERMINATION OF STATISTICS FOR ANY ROTATION OF AXES

OF A BIVARIATE NORMAL ELLIPTICAL DISTRIBUTION

The information in this report has been reviewed for security classification. Review of any information concerning Department of Defense or Atomic Energy Commission programs has been made by the MSFC Security Classification officer. This report, in its entirety, has been determined to be unclassified.

This document has also been reviewed and approved for technical accuracy.
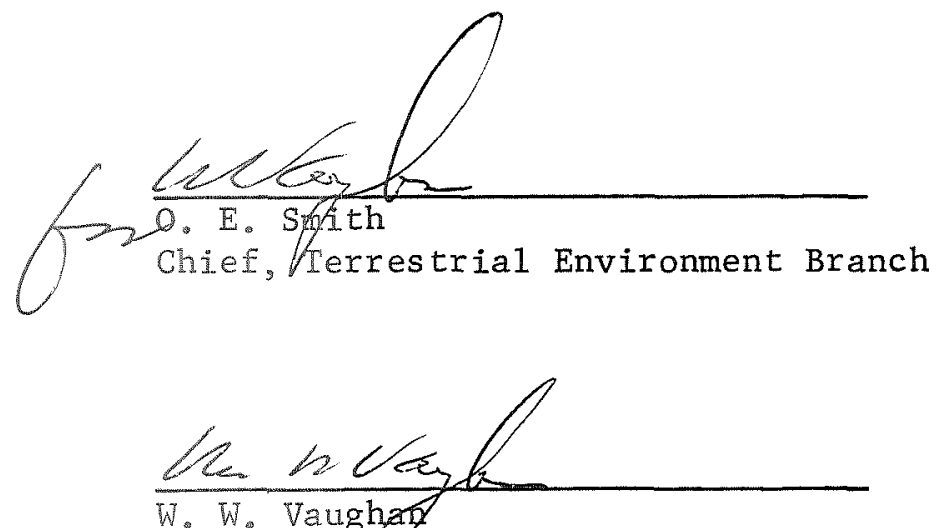

Chilef, Aerópace Environment Division

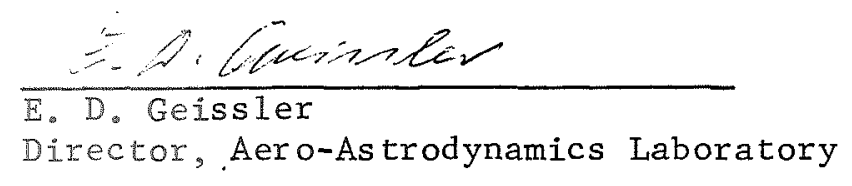

